direct pulp capping with $\mathrm{Ca}(\mathrm{OH}) 2$, MTA, biodentine, and dentin bonding system in human teeth. J Endod. 2015;41:1234-1240.

8. Rajasekharan S, Martens LC, Vandenbulcke J, et al (2016). Efficacy of three different pulpotomy agents in primary molars: a randomized control trial. Epub, 50, 3, 215-228.

9. Nasrallah H, El Noueiri B, Pilipili C, Ayoub F. Clinical and Radiographic Evaluations of Biodentine ${ }^{\mathrm{TM}}$ Pulpotomies in Mature Primary Molars (Stage 2). Int J Clin Pediatr Dent. 2018;11(6):496-504.

\title{
ĐÁNH GIÁ SỰ THAY ĐỔI CÁC THÔNG SỐ Pa02/FiO2, SP02/FiO2 TRONG QUÁ TRÌNH ĐIỀU TRI VÀ KẾT QUẢ ĐIỀU TRI BÊNH NHÂN SUY HÔ HẤP TIẾN TRIỂN DO CÚM A TẠI BỆNH VIỆN BÊ̂NH NHIỆT ĐỚI TRUNG ƯO'NG (2019-2021)
}

\section{TÓM TẮT}

Muc tiêu: mô tả được sự thay đổi các thông số $\mathrm{PaO} 2 / \mathrm{FiO} 2, \mathrm{SPO} 2 / \mathrm{FiO} 2$ trong quá trình điêu trị và kết quả điều trị bệnh nhân suy hô hấp tiến triển do cúm $A$ tai Bênh viên Bênh nhiêt đới Trung Ương (2019 2021). Đối tượng \& phương pháp: mô tả cắt ngang 30 bếnh nhân suy hô hấp tiến triển (ARDS) do cúm $A$. Kết quả: ở nhóm bệnh nhân sống sót chỉ số $\mathrm{PaO} 2 / \mathrm{FiO} 2$ tăng dần trong quá trình điều trị, mức tăng có ý nghĩa với $\mathrm{p}<0,05$. Nhóm bệnh nhân tử vong, ch số $\mathrm{PaO} 2 / \mathrm{FiO} 2$ có xu hướng không thay đổi trong quá trình điều trị, sự khác biệt không có ý nghĩa với $\mathrm{p}>$ 0,05 . Tỷ số $\mathrm{PaO} 2 / \mathrm{FiO} 2$ và $\mathrm{SPO} 2 / \mathrm{FiO} 2$ trước điều trị có liên quan với tỷ lệ tử vong. Diện tích dưới đường cong AUC của $\mathrm{PaO} 2 / \mathrm{FiO} 2$ là 0,625 , điểm cắt là 90 thì độ nhạy và độ đặc hiệu của tiên đoán tử vong lân lượt là $89 \%$ và $42 \%$. Diển tích dưới đường cong AUC của SPO2/FiO2 là 0,727, điểm cắt là 116 , độ nhạy và độ đặc hiệu của tiên đoán tử vong lần lượt là $89 \%$ và $58 \%$. Tỷ lệ tử vong chung trong nghiên cứu là $40 \%$.

Tư khóa: Hội chứng suy hô hấp cấp tiến triển (ARDS), cúm $A$.

\section{SUMMARY \\ DESCRIBE THE CHANGE OF PARAMETERS PAO2/FIO2, SPO2/FIO2 DURING TREATMENT AND TREATMENT RESULTS OF PATIENTS WITH ACUTE RESPIRATORY DISTRESS SYNDROMECAUSED (ARDS) CAUSED BY INFLUENZA A AT THE NATIONAL HOSPITAL OF TROPICAL DISEASES (2019 - 2021) \\ Objective: Describe the change of parameters} $\mathrm{PaO} 2 / \mathrm{FiO2}$, SPO2/FiO2 during treatment and treatment results of patients with Acute Respiratory Distress Syndromecaused (ARDS) caused by influenza $A$ at the National Hospital of Tropical Diseases (2019

* Đai hoc Y Hà Nôi

Chịu trách nhiệm chính: Trần Văn Giang

Email: giangminh08@gmail.com

Ngày nhân bài: 14.9.2021

Ngày phản biên khoa hoc: 12.11.2021

Ngày duyệt bài: 22.11.2021
Trần Văn Giang*, Trương Tư Thế Bảo*

- 2021). Materials and methodes: Cross-sectional description of 30 patients with Acute Respiratory Distress Syndromecaused (ARDS) caused by influenza A. Results: In the group of surviving patients, the $\mathrm{PaO} 2 / \mathrm{FiO} 2$ index gradually increased during treatment, the increase was significant with $p<0.05$. In the group of patients who died, the $\mathrm{PaO} 2 / \mathrm{FiO}_{2}$ index tended to remain unchanged during treatment, the difference was not significant with $\mathrm{p}>0.05$. Pretreatment $\mathrm{PaO} 2 / \mathrm{FiO} 2$ and $\mathrm{SPO} 2 / \mathrm{FiO} 2$ ratios are associated with mortality. The area under the curve (AUC) of $\mathrm{PaO} 2 / \mathrm{FiO} 2$ was 0.625 , the cut-off point was 90 , the sensitivity and specificity of mortality prediction were $89 \%$ and $42 \%$. The area under the curve (AUC) of $\mathrm{SPO} 2 / \mathrm{FiO} 2$ was 0.727 , the cut-off point was 116 , and the sensitivity and specificity of mortality prediction were $89 \%$ and $58 \%$. Overall mortality in the study was $40 \%$.

Keywords: Acute Respiratory Distress Syndromecaused (ARDS), Influenza A.

\section{I. ĐĂT VẤN ĐỀ}

Cúm là một bệnh truyền nhiễm cấp tính của đường hô hấp, do virus cúm gây ra. Bệnh có thể diễn biến từ nhẹ đến nguy kịch như viêm phổi, suy hô hấp cấp, suy đa tạng và tử vong. Người già, trẻ em, hoắc người có cơ địa đặc biêt như mắc bệnh mạn tính, béo phì, suy giảm miến dịch có nguy cơ tiến triển nặng cao hơn [1].

Hội chứng suy hô hấp cấp tiến triển (ARDS) là một hội chứng bệnh lý trong đó màng phế nang mao mạch của phổi bị tổn thương cấp tính do nhiều nguyên nhân khác nhau dẫn đến tình trạng suy hô hấp nặng không đáp ứng với thở oxy liều cao[2]. ARDS là biến chứng hay gặp và gây tử vong nhiều nhất ở bệnh nhân nhiễm cúm $A$.

Hằng năm, trên toàn cầu, có hơn 10 triệu người phải nhập viện do cúm, gây ra 100.000 200.000 ca từ vong [3]. Tỷ lê chung của ARDS khoảng 150 trên 100000 ca bệnh, chiếm 10 $15 \%$ số bệnh nhân điều trị tại các đơn vị hồi sức. Tỷ lệ tử vong tại viện trung bình là $24 \%$ và tỷ lệ 
tử vong trong 1 năm đầu do hậu quả của bệnh lên tới 40\%. Tại Việt Nam giai đoạn 2006 - 2015, tỷ lệ viêm phổi nặng do cúm chiếm $16,9 \%$, trong đó $50,2 \%$ ca viêm phổi nặng là do cúm phân typ $\mathrm{A} / \mathrm{H} 1 \mathrm{~N} 1 / 09$.

Đứng trước sự biến đổi khó lường của virus cúm $A$ và tỷ lệ di chứng cũng như tỷ lệ tử vong của ARDS còn cao, việc đánh giá và theo dõi quá trình điều trị là cần thiết. Do đó chúng tôi tiến hành nghiên cứu: "Đánh giá sự thay đổi các thông số $\mathrm{PaO} 2 / \mathrm{FiO} 2, \mathrm{SPO} 2 / \mathrm{FiO} 2$ trong quá trình điều trị và kết quả điều trị bệnh nhân suy hô hấp tiến triển do cúm $A$ tại Bệnh viện Bệnh nhiệt đới Trung Ương (2019-2021)"

\section{II. ĐỐI TƯỢNG VÀ PHƯƠNG PHÁP NGHIÊN CỨU}

2.1. Đối tượng nghiên cứu. Gồm 30 bệnh nhân được chẩn đoán ARDS do cúm $A$ điều trị tại Bệnh viện Bệnh Nhiệt đới Trung Ương, trong thời gian từ tháng $7 / 2019$ đến $6 / 2021$.

Tiêu chuân lựa chọn: Bệnh nhân được chẩn đoán và phân loại ARDS theo tiêu chuẩn Bộ Y Tế 2015 và tiêu chuẩn Berlin 2012 [2] bao gồm: Suy hô hấp khởi phát trong vòng 1 tuần, xuất hiện triệu chứng mới hoặc nặng hơn. Suy hô hấp khồng giải thích đầy đủ do suy tim hoặc quá tải dịch. Nếu không có yếu tố nguy cơ thì cần siêu âm tim để loại trừ. $X$ quang phổi: có hình ảnh tổn thương mờ 2 bên phổi không phải do tràn dịch, xẹp phổi hoặc u/nốt. Thiếu oxy: PaO2/FiO2 $(P / F) \leq 300$ với PEEP hoăc CPAP $\geq 5 \mathrm{cmH} 2 \mathrm{O}$. ARDS nhe: $200<\mathrm{PaO} 2 / \mathrm{FiO} 2 \leq 300$ với PEEP hoặc CPAP $\geq 5 \mathrm{cmH} 2 \mathrm{O}$. ARDS vừa: $100<$ $\mathrm{PaO} 2 / \mathrm{FiO} 2 \leq 200$ với PEEP $\geq 5 \mathrm{cmH} 2 \mathrm{O}$. ARDS nặng: $\mathrm{PaO} 2 / \mathrm{FiO} 2 \leq 100$ với PEEP $\geq 5 \mathrm{cmH} 2 \mathrm{O}$.

- Tiêu chuấn loại trừ: bệnh nhân < 16 tuổi hoặc bệnh nhân mắc HIV/AIDS hoặc cấy máu và dịch đường hô hấp dương tính với căn nguyên khác: vi khuẩn, vi nấm, lao... trong vòng 48 giờ sau khi nhập viện.

2.2. Địa điểm và thời gian nghiên cứu. Tại Bệnh viện Bệnh Nhiệt đới Trung Ương từ tháng $7 / 2019$ đến $6 / 2021$.

\subsection{Phương pháp nghiên cứu}

- Thiết kế nghiên cứu: mô tả cắt ngang, kết hợp hồi cứu và tiến cứu. Hồi cứu: từ $01 / 07 / 2019$ đến 30/06/2020. Tiến cứu: từ 01/07/2020 đến 30/06/2021

- Cỡ mẫu nghiên cứu: tất cả bệnh nhân đủ tiêu chuẩn vào nghiên cứu trong thời gian 1/7/2019 đến 30/06/2021 sẽ được thu thập.

- Các thức thu thập thông tin: thông tin bệnh nhân được thu thập theo một mẫu bệnh án. Bệnh nhân được chia thành 3 nhóm ARDS nhẹ, ARDS vừa và ARDS nặng.

- Phân tích và xử lý số liệu: số liệu được thu thập và xử lý bằng phần mềm SPSS 22.0.

\section{KẾT QUẢ NGHIÊN CỨU}

3.1. Sự thay đổi chỉ số $P / F$ trước và sau điêuu trị

Bảng 1. Sự thay đổi chi số P/F trước và sau điều trị

\begin{tabular}{|c|c|c|c|c|c|c|c|}
\hline P/F (X I SD) & N1 & N2 & N3 & N4 & N5 & N6 & N7 \\
\hline Nhóm sống & $145,3 \pm$ & $164,2 \pm$ & $181,1 \pm$ & $196,7 \pm$ & 244,7 & $280,4 \pm$ & $315,8 \pm$ \\
& 13,9 & 13,1 & 17,4 & 16,3 & $\pm 20,2$ & 24,1 & 24,6 \\
\hline \multirow{2}{*}{ Nhóm tử vong } & $122,4 \pm$ & $135,2 \pm$ & $121,1 \pm$ & $139,5 \pm$ & $163,3 \pm$ & $151,1 \pm$ & $123,9 \pm$ \\
& 15,2 & 18,3 & 15,2 & 21,2 & 38,3 & 31,9 & 31,1 \\
\hline & $136,2 \pm$ & $152,6 \pm$ & $158,3 \pm$ & $175,6 \pm$ & $219,5 \pm$ & $244,2 \pm$ & $267,9 \pm$ \\
Chung & 56,8 & 59,7 & 71,6 & 72,5 & 98,9 & 112 & 128 \\
\hline
\end{tabular}

Nhận xét: Ớ nhóm chung và nhóm sống sót chỉ số $\mathrm{P} / \mathrm{F}$ tăng dần trong quá trình điều trị, mức tăng có ý nghĩa $\mathrm{p}<0,05$. Ở nhóm tử vong, chỉ số P/F có xu hướng không thay đổi trong quá trình điều trị, sự khác biệt không rõ rệt, $\mathrm{p}>0,05$.

3.2. Liên quan giữa PaO2/FiO2 và SPO2/FiO2 (S/F) trước điêuu trị với tỷ lệ tử vong

Bảng 2. Liên quan giữa P/F và S/F trước điều trị với tỷ lệ tử vong

\begin{tabular}{|c|c|c|c|c|c|c|c|}
\hline \multirow{2}{*}{\multicolumn{2}{|c|}{ Chỉ số }} & \multicolumn{2}{|c|}{ Sống } & \multicolumn{2}{|c|}{ Tử vong } & \multirow[b]{2}{*}{$\mathbf{p}$} & \multirow[b]{2}{*}{ OR (95\%CI) } \\
\hline & & $\mathbf{n}$ & $\%$ & $\mathbf{n}$ & $\%$ & & \\
\hline \multirow{2}{*}{$\mathrm{P} / \mathrm{F}$} & $>90$ & 14 & 77,8 & 4 & 22,2 & \multirow{2}{*}{0,02} & \multirow{2}{*}{$7(1,36-35,93)$} \\
\hline & $\leq 90$ & 4 & 33,3 & 8 & 66,7 & & \\
\hline \multirow{2}{*}{$S / F$} & $>116$ & 16 & 76,2 & 5 & 23,8 & \multirow{2}{*}{0,013} & \multirow{2}{*}{$\begin{array}{c}11,2(1,74- \\
72,3)\end{array}$} \\
\hline & $\leq 116$ & 2 & 22,2 & 7 & 77,8 & & \\
\hline
\end{tabular}


Nhận xét: Tỷ số $\mathrm{P} / \mathrm{F}$ và $\mathrm{S} / \mathrm{F}$ trước điều trị có liên quan với tỷ lệ tử vong. Tỷ lệ tử vong của nhóm bệnh nhân có $P / F \leq 90$ cao hơn so với nhóm bệnh nhân có $P / F>90$ với $p=0,02, O R=7(95 \% C I$ : $1,36-35,93)$. Tỷ lệ tử vong của nhóm bệnh nhân có $S / F \leq 116$ cao hơn so với nhóm bệnh nhân có S/F > 116 với $p=0,013$, OR là 11,2 (95\%CI: $1,74-72,3)$.

Bảng 3. Diên tích dưới đường cong ROC và điểm cắt của giá trị P/F và S/F trong tiên đoán tử vong ở bệnh nhân ARDS do cúm $A$

\begin{tabular}{|c|c|c|c|c|}
\hline Chî số & AUC (95\%CI) & Điếm căt & Độ nhạy & Độ đặc hiệu \\
\hline P/F & $0,625(0,412-0,838)$ & 90 & 89 & 42 \\
\hline S/F & $0,727(0,521-0,933)$ & 116 & 89 & 58 \\
\hline
\end{tabular}

Nhận xét: Diện tích dưới đường cong của $\mathrm{P} / \mathrm{F}$ là 0,625 , với điếm cắt là 90 thì độ nhạy và độ đặc hiệu của tiên đoán tử vong lần lượt là $89 \%$ và $42 \%$. Diện tích dưới đường cong của $S / F$ là 0,727 , với điểm cắt cắt là 116 thì độ nhạy và độ đặc hiệu của tiên đoán tử vong lần lượt là $89 \%$ và $58 \%$.

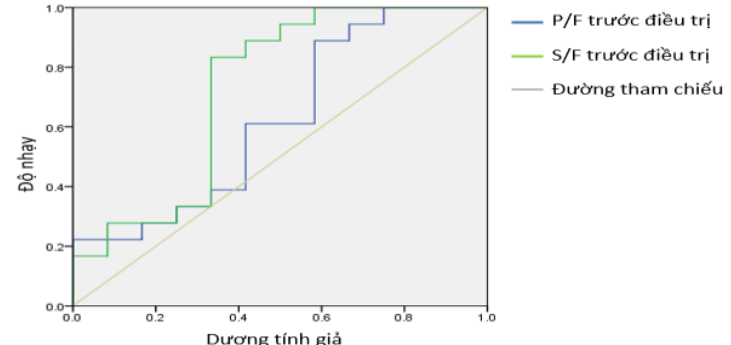

Biểu đồ 1: Diện tích dưới đường cong ROC của $P / F$ và $S / F$ trong tiên lượng tử vong ở bệnh nhân ARDS do cúm $A$ cúm A

3.3. Kết quả điêu trị bệnh nhân ARDS do

Bảng 4. Kết quả điều trị bệnh nhân ARDS do cúm $A$

\begin{tabular}{|c|c|c|c|c|}
\hline $\begin{array}{c}\text { Nhóm bệnh } \\
\text { nhân }\end{array}$ & \multicolumn{2}{|c|}{ Sống } & \multicolumn{2}{c|}{ Tử vong } \\
\cline { 2 - 5 } & $\mathbf{n}$ & $\mathbf{\%}$ & $\mathbf{n}$ & $\mathbf{\%}$ \\
\hline Chung $(n=30)$ & 18 & 60 & 12 & 40 \\
\hline Nhẹ $(n=5)$ & 4 & 80 & 1 & 20 \\
\hline Vừa $(n=15)$ & 9 & 60 & 6 & 40 \\
\hline Nặng $(n=10)$ & 5 & 50 & 5 & 50 \\
\hline Chung $(n=30)$ & 18 & 60 & 12 & 40 \\
\hline
\end{tabular}

Nhận xét: Tỳ lệ tử vong trong nhóm nghiên cứu là 12 bệnh nhẩn (chiếm 40\%). Trong đó tỷ lệ tử vong trong nhóm bệnh nhân nặng là $50 \%$, nhóm vừa là $40 \%$ và nhóm nhẹ là $20 \%$.

\section{BÀN LUẬN}

4.1. Sự thay đổi chỉ số $P / F$ trước và sau điêu trị. Trong nghiên cứu của chúng tôi cho thấy sau điêu trị có sự cải thiện rõ về tỷ lệ $P / F$ so với trước điều trị, thay đổi này có nghĩa thống kê với $\mathrm{p}<0,05$. Đặc biệt ở nhóm bệnh nhân sống, tỷ lệ $P / F$ trung bình trước điêuu trị là 145,3 tăng lên là 181,1 ở ngày thứ 3 của điều trị và tăng lên 315 ở thời điểm ngày thứ 7 của điều trị (Bảng 1 ). Kết quả trên cũng tương tự kết quả nghiên cứu của Lương Quốc Chính: tî lệ P/F tăng dần theo thời gian và đều khác biệt có ý nghĩa thống kê giữa các thời điểm nghiên cứu với $p<0,01$ [4]. Kết quả nghiên cứu của ARDS Network: P/F đo ở ngày $1,3,7$ tương ứng là $158 \pm 73 ; 160 \pm 68$; $165 \pm 71$ [5]; nghiên cứu của Meade: 149,1 \pm 60,$6 ; 164,1 \pm 63,5$ và $180,8 \pm 73,0$ [6]. Điêu này cho thấy sự cải thiện $\mathrm{P} / \mathrm{F}$ trong quá trình thông khí nhân tạo cũng là một dấu hiệu giúp tiên lượng kết quả điều trị của ARDS.

4.2. Liên quan giữa $P / F$ và $S / F$ trước điêu trị với tỷ lệ tử vong. Kết quả ở bảng 2 cho thấy cả hai chỉ số $P / F$ và $S / F$ đều có liên quan với tỷ lệ tử vong ở bệnh nhân ARDS. Diên tích dưới đường cong ROC của P/F là 0,625 . Với điểm cắt phân tách là 90 thì có giá trị tiên lượng tỷ lệ tử vong với độ nhạy $89 \%$ và độ đặc hiệu $42 \%$. Kết quả nghiên cứu của chúng tồi cho thấy bệnh nhân có $\mathrm{P} / \mathrm{F} \leq 90$ có tỷ lệ tử vong cao gấp 7 lần (95\%CI: 1,364 - 35,93) so với nhóm bênh nhân có chỉ số $\mathrm{P} / \mathrm{F}>90$, sự khác biệt là có ý nghĩa thống kê với $p=0,02$. Diện tích dưới đường cong ROC của S/F là 0,727 , với điểm cắt phân tách 116 thì độ nhạy là $89 \%$ và độ đặc hiệu $58 \%$. Bệnh nhân có $S / F \leq 116$ có tỷ lệ tử vong cao hơn nhóm bệnh nhân có $S / F>116$, có ý nghĩa với $p=0,013, \mathrm{OR}=11,2(95 \% \mathrm{CI}: 1,74-72,3)$.

4.3. Kết quả điêuu trị bệnh nhân viêm phổi ARDS do cúm. Tỷ lệ tử vong chung của bệnh nhân ARDS trong nghiên cứu này của chúng tôi là 40\%. Trong đó tỷ lệ tử vong tương ứng mức độ nhẹ, vừa, nặng của bệnh lần lượt là $20 \%, 40 \%$ và $50 \%$. Kết quả trên tương đồng với nghiên cứu của Bellani và cộng sự tiến hành trên 459 đơn vị điêu trị tích cực ở 50 quốc gia trên khắp 5 chầu lục trong thời gian 4 năm cho tỷ lê bệnh nhân nhẹ là $30 \%$, vừa là $46,6 \%$ và bệnh nhân nặng 23,4\% [7]. Tuy nhiên theo nghiên cứu của Lương Quốc Chính và cộng sự trên 126 bệnh nhân ARDS nhập viện tại 3 viện tuyến trung ương cho kết quả khác biệt về tỷ lệ của 3 nhóm bệnh nhân nhẹ, vừa, nặng lần lượt là $9,5 \%$, $37,3 \%$ và $53,2 \%$ [4]. Sở dĩ có sự khác biệt trên là do nghiên cứu của chúng tôi được tiến hành tại bệnh viện chuyên khoa tuyến trung ương, trên các bệnh nhân ARDS do 1 căn nguyên xác 
định là cúm $A$, các bệnh nhân khi nhập viện thường đã qua các tuyến cơ sở và được điều trị ban đâu hoặc chỉ định thuốc kháng virus ngay khi nhập viện.

\section{KẾT LUẦN}

Tỷ lệ tử vong chung của các bệnh nhân suy hô hấp cấp tiên triển do cúm $\mathrm{A}$ tương đối cao (40\%). Hai chỉ số $\mathrm{PaO} 2 / \mathrm{FiO} 2$ và $\mathrm{SPO} / \mathrm{FiO} 2$ có giá trị tiên lượng tử vong ở bệnh nhân ARDS do cúm A.

\section{TÀI LIÊU THAM KHẢO}

1. Mertz D, Kim T.H, Johnstone J, et al. (2013). Populations at risk for severe or complicated influenza illness: systematic review and metaanalysis. Bmj. 347.

2. Task, F.A.D., Ranieri V.M, Rubenfeld G.D, et al. (2012). Acute respiratory distress syndrome. Jama. 307(23):2526-2533.

3. Troeger C.E, Blacker B.F, Khalil I.A, et al. (2019). Mortality, morbidity, and hospitalisations due to influenza lower respiratory tract infections, 2017: an analysis for the Global Burden of Disease Study 2017. The Lancet Respiratory Medicine. 7(1):69-89.

4. Lương Quốc Chính, Manabe T, Đố Ngọc Sơn, et al. (2019). Clinical epidemiology and mortality on patients with acute respiratory distress syndrome (ARDS) in Vietnam. PloS one. 14(8):e0221114.

5. Acute Respiratory Distress Syndrome Network. (2000). Ventilation with lower tidal volumes as compared with traditional tidal volumes for acute lung injury and the acute respiratory distress syndrome. New England Journal of Medicine. 342(18):1301-1308.

6. Meade M.O, Cook D.J, Guyatt G.H, et al. (2008). Ventilation strategy using low tidal volumes, recruitment maneuvers, and high positive end-expiratory pressure for acute lung injury and acute respiratory distress syndrome: a randomized controlled trial. Jama. 299(6):637-645.

7. Bellani G, Laffey J.G, Eddy F, et al. (2016). Epidemiology, patterns of care, and mortality for patients with acute respiratory distress syndrome in intensive care units in 50 countries. Jama. 315(8):788-800.

\title{
THỰC TRANG SỬ DỤNG THANG ĐIỂM GUSS CỦA ĐIỀU DƯỠNG VIÊN TRONG CHĂM SÓC RỐI LOAN NUỐT Ở NGƯỜI BÊNNH ĐộT QUY NÃO TẠI TRUNG TÂM ĐộT QUỴ - BỆNH VIÊ̂N HỮU NGHỊ ĐA KHOA NGHỆ AN NĂM 2021
}

\author{
Nguyễn Ngọc Hoà ${ }^{1}$, Đinh Thị Hằng $\mathrm{Nga}^{2}$, Đỗ Quang Minh ${ }^{2}$
}

\section{TÓM TẮT}

Mục tiêu: Mô tả thực trạng sử dụng thang điểm Guss của điêuu dưỡng viên trong chăm sóc rối loạn nuốt ở người bệnh đột quy não tại Trung tâm Đột quy. - Bênh viên Hữu Nghi đa khoa Nghê An năm 2021. Đối tượng: điều dưỡng viên làm việc tại Trung tâm Đột quỵ bệnh viện Hữu Nghị đa khoa Nghệ An đồng ý tham gia nghiên cứu. Phương pháp nghiên cứu: mô tả cắt ngang, có phân tích. Kết quả: Tỉ lê ĐDV xác định được kết quả test nuốt thông qua việc sử dụng thang điểm Guss chiếm tỉ lệ cao (100\%). Tuy nhiên việc đánh giá Sp02 của người bệnh chiếm tỉ lệ thấp nhẩt $(2,5 \%)$. Vì vâyy cân thực hiên đầy đủ các nội dung của thang điểm Guss để đặt hiệu quả cao trong chăm sóc người bệnh đột quy.

Tư khóa: thang điểm Guss, điêu dưỡng viên, chăm sóc, rối loạn nuốt, người bệnh, đột quy. não

\section{SUMMARY \\ CURRENT SITUATION OF USING THE GUSS}

\footnotetext{
${ }^{1}$ Bệnh viện Hữu nghị đa khoa tỉnh Nghệ An

2Trường đai hoc Y khoa Vinh

Chịu trách nhiệm chính: Nguyễn Ngọc Hòa

Email: drnguyenngochoa@gmail.com

Ngày nhận bài: 15.9.2021

Ngày phản biên khoa hoc: 15.11.2021

Ngày duyệt bài: 24.11.2021
}

\section{SCORE BY NURSING STAFFS IN CARING SWALLOWING DISORDERS OF PATIENTS WITH BRAIN STROKE AT THE STROKE CENTER - NGHE AN GENERL FRIENSHIP HOSPITAL IN 2021}

Objectives: 1.Describe the current situation of using the Guss score of nursing staffs in caring the swallowing disorders of brain stroke patients at Stroke Center - Nghe An General Frienship Hospital in 2021. Subjects: nursing staffs working at the Stroke Center - Nghe An General Friendship Hospital Nghe An agreed to participate in the study. Research method: cross-sectional descriptive, analytical. Results: The percentage of nurses who can determine the swallowing test results through the use of the Guss scale accounts for a high percentage $(100 \%)$. However, the assessment of Sp02 of patients accounted for the lowest rate (2.5\%). Therefore, it is necessary to fully implement the contents of the Guss scale to place high efficiency in stroke care.

Keywords: GUSS score, nursing staffs, care, swallowing disorders, patients, stroke

\section{I. ĐĂT VẤN ĐỀ}

Đột quy não là một trong những bệnh thường gặp và để lại biến chứng nặng nề cho người bệnh, ảnh hưởng đến cuộc sống của người bệnh 